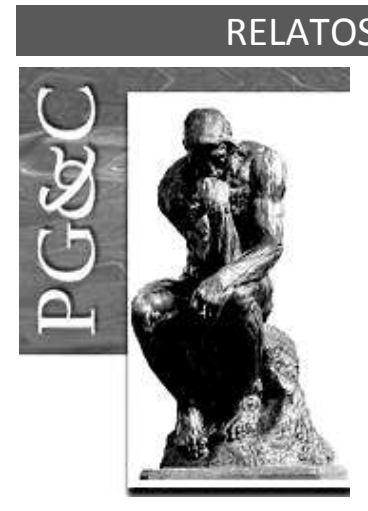

\title{
A GESTÃO DO CONHECIMENTO APLICADA À POLÍTICA PÚBLICA DE ESPORTE E LAZER
}

\author{
Luiz Carlos Pessoa Nery \\ Doutor em Ciências do Exercício e Esporte pela Universidade Estadual do \\ Rio de Janeiro, Brasil. Professor do Instituto Federal de Educação, Ciência e \\ Tecnologia do Sudeste de Minas Gerais, Brasil. \\ E-mail: gestaoesporte@yahoo.com.br \\ Pedro Henrique Iglesiaz Menegaldo \\ Mestre em Educação Física pela Universidade Estadual de Maringá, Brasil. \\ E-mail: pedromenegaldo@hotmail.com \\ Temístocles Damasceno Silva \\ Mestre em Desenvolvimento Regional e Urbano pela Universidade de Salvador, \\ Brasil. Professor da Universidade Estadual do Sudoeste da Bahia, Brasil. \\ E-mail: tom@uesb.edu.br
}

\section{Resumo}

O artigo tem como objetivo apresentar a gestão do conhecimento enquanto instrumento aplicável a política pública de esporte e lazer, levando-se em consideração as diversas etapas que compõem o ciclo da política. Para tal, elenca os pressupostos teóricos que permeiam a temática relacionando-os com as fases da política (formação da agenda, formulação, implementação e avaliação) no contexto esportivo. A partir dos dados são evidenciados nas fases do ciclo político os tipos e fontes de informações para sistematização da gestão do conhecimento no universo das políticas de esporte e lazer, envolvendo informações que permitem diagnosticar, acompanhar e avaliar o gerenciamento das ações mediante o levantamento de elementos que envolvem indicadores sociais, aspectos legais e burocráticos, os múltiplos agentes envolvidos, recursos orçamentários, recursos humanos e materiais, dentre outros. As reflexões indicam um caminho para o processo de institucionalização da gestão do conhecimento no âmbito da gestão pública deste setor, porém ressalta também as limitações e fragilidades presentes nos contextos governamentais. De modo geral, conclui que a gestão do conhecimento se apresenta como uma ferramenta salutar a ser utilizada pelos gestores esportivos no sentido de sistematizar o fluxo de conhecimentos produzido pelo processo político em questão, bem como, organizar tais informações com vistas à qualificação da tomada de decisão com base em evidências técnico-científicas.

Palavras-chave: Políticas Públicas. Gestão do Conhecimento. Fluxo de Conhecimentos. Esporte e Lazer. Inovação.

\section{KNOWLEDGE MANAGEMENT APPLIED TO PUBLIC SPORTS AND LEISURE POLICIES}

\begin{abstract}
The article aimed to present knowledge management as an instrument applicable to public sports and leisure policy, taking into account the various stages that make up the policy cycle. For this purpose, this essay listed the theoretical assumptions that permeate the theme, relating them to the phases of the policy (agenda formation, formulation, implementation and evaluation) in the sports context. From the data, the types and sources of information for the systematization of knowledge management in the universe of sports and leisure policies are evidenced in the phases of the political cycle, involving information that allows diagnosing, monitoring and evaluating the management of actions through the survey of elements which involve social indicators, legal and bureaucratic aspects, the multiple agents involved, budgetary resources, human and material resources, among others. The reflections indicate a
\end{abstract}

Perspectivas em Gestão \& Conhecimento, João Pessoa, v. 11, número especial, p. 83-96, mar. 2021.

DOI: http://dx.doi.org/10.22478/ufpb.2236-417X.2021v11nEspecial.57166

http://periodicos.ufpb.br/ojs2/index.php/pgc. ISSN: 2236-417X. Publicação sob Licença (cc) EY-NC-ND 
path for the process of institutionalizing knowledge management within the scope of public management in this sector, but it also highlights the limitations and weaknesses present in government contexts. In general, it is concluded that knowledge management presents itself as a healthy tool to be used by sports managers in order to systematize the flow of knowledge produced by the political process in question, as well as organize such information with a view to qualifying the decision-making based on technical-scientific evidence.

Keywords: Public policies. Knowledge Management. Flow of Knowledge. Sports and Leisure. Innovation.

\section{INTRODUÇÃO}

A Gestão do Conhecimento se apresenta como um elemento de inovação no campo da gestão pública brasileira, sendo constituída por práticas de compartilhamento e transferência de conhecimentos por meio de processos, técnicas e ferramentas, muitas vezes já existentes nas organizações, mas que não são reconhecidas como procedimentos de gerenciamento de informações e conhecimentos das instituições (BATISTA, 2004), e por vezes, não certificandose das potencialidades dessa área para o setor público.

De acordo com Colauto e Beuren (2003), na década de 1990 a gestão do conhecimento surgiu na perspectiva de potencializar o valor agregado a determinada informação e, ao mesmo tempo, otimizar a interação comunicacional das organizações. Entretanto, torna-se necessário compreender que a proposta atual delineada para a gestão do conhecimento perpassa pela configuração de um novo campo de interação entre a Tecnologia da Informação e a Administração.

Do ponto de vista contemporâneo, alguns estudos indicam que a gestão pública vem sofrendo mudanças organizacionais como resultados de adoção das práticas de gestão do conhecimento, principalmente no alargamento do relacionamento entre as instituições, ampliação da transparência dos procedimentos institucionais e expansão da aplicação de tecnologia da informação e comunicação. Por meio desses processos decorre-se certa tendência de ampliação da eficiência das organizações (OCDE, 2002; ROSENBERG; OHAYON; BATISTA, 2004). Na compreensão desta ferramenta teórica, com capacidade de projeção prática do conhecimento e comportamentos gerenciais, ressalta-se que este fenômeno no Brasil pode ser entendido com uma importante fonte de vantagens, desde que sejam atendidos os requisitos de eficiência gerencial e financeira (SZEZERBICKI, 2006).

Sobre este aspecto, a gestão do conhecimento pode ser compreendida a partir da perspectiva de suas práticas e sistemas. As práticas da gestão do conhecimento envolvem a produção, retenção, disseminação, compartilhamento e aplicação do conhecimento no interior das organizações e suas relações com o mundo externo. Já o sistema de gestão do conhecimento trata-se do agrupamento de práticas distintas e interligadas que visam claramente melhorar os aspectos de desempenho organizacional das instituições, desde que alinhadas à missão, visão de futuro e estratégias da organização (BATISTA, 2004).

$\mathrm{Na}$ área esportiva, o advento do Ministério do Esporte no ano de 2003 e os megaeventos esportivos sediados pelo Brasil na última década proporcionaram um novo panorama para o esporte no país. A nova dinâmica correlata à política em questão estabeleceu a necessidade de aquisição de conhecimentos por parte dos gestores esportivos, no sentido de qualificar os processos políticos do esporte e lazer.

Apesar do imenso volume de recursos financeiros destinados ao setor, foram raríssimas as iniciativas de preenchimento da lacuna existente no campo da gestão do conhecimento que permeia a área. Segundo Capela (2018, p. 10), o estabelecimento de prioridades das pautas encontra-se relacionado à definição da agenda, enquanto o

Perspectivas em Gestão \& Conhecimento, João Pessoa, v. 11, número especial, p. 83-96, mar. 2021. 
delineamento do plano de ação está vinculado a definição de alternativas. Para a autora em questão, o estudo sobre a formulação de políticas públicas desdobra-se na possibilidade de entender por que "[...] alguns assuntos se tornam importantes e acabam concentrando o interesse de vários atores, enquanto outros não. E também porque algumas alternativas são seriamente consideradas, enquanto outras são descartadas".

Ao direcionar o olhar para outra esfera de intervenção pública no esporte, nesse caso para os municípios brasileiros, algumas iniciativas pontuais e fragmentadas foram desenvolvidas ao longo do percurso de gerenciamento de ações nesse contexto. No entanto, percebe-se a carência de ações significativas no âmbito da gestão do conhecimento, que eventualmente, pode ocasionar uma série de efeitos colaterais negativos e/ou limitadores de desenvolvimento para o erário público, tendo em vista a falta de compreensão por parte de alguns gestores esportivos em relação aos conceitos e elementos da administração pública em geral e consequentemente, resultando em dificuldades na condução das atividades a serem implementadas. Além disso, o conhecimento sobre componentes fundamentais para a materialização de políticas públicas em contextos sociais democráticos pode ser escasso, a saber: gestão participativa; governança; princípio de efetividade das ações.

Um dado que reforça esse panorama trata-se do levantamento do Instituto Brasileiro de Geografia e Estatística (IBGE) no ano de 2016, vindo a indicar que a maior parte dos agentes públicos responsáveis pela gestão esportiva dos municípios brasileiros ainda não possuem formação profissional. A pesquisa coletou dados na maioria dos municípios brasileiros ( $\mathrm{n}=$ 4.701), sendo que, mais de $50 \%$ dessas localidades apresentavam gestores esportivos sem formação superior completa (IBGE, 2016). Ao mesmo tempo, a pesquisa diagnosticou que as unidades administrativas direcionadas ao esporte e lazer encontram-se subordinadas a outras pastas e não apresentam autonomia financeira. Além disso, os agentes inseridos nessas entidades, em sua grande maioria, ocupam cargos comissionados sem previsão de prérequisitos mínimos para a assunção à função.

Esses dados endossam a precariedade da gestão do esporte nacional bem como, indicam a necessidade de uma ação voltada ao processo de gestão do conhecimento aplicada à referida área. Levando-se em consideração os aspectos e processos supracitados, para se alcançar êxito no desempenho das organizações públicas torna-se, em certa medida, necessário compreender que a gestão do conhecimento requer estar presente em todas as etapas da política pública. No campo acadêmico, existe uma vasta discussão sobre o modelo do ciclo de políticas, com diferentes classificações (SECCHI, 2010), porém é possível verificar que algumas fases são sempre recorrentes, sendo essas: formação de agenda, formulação, implementação e avaliação das políticas públicas (FREY, 2000; COSTA; CASTANHAR, 2003; RAMOS; SCHABBACH, 2012).

Diante do exposto, o presente trabalho teve como objetivo apresentar a gestão do conhecimento enquanto ferramenta aplicável a política pública de esporte e lazer, levando- se em consideração as diversas etapas que compõem o referido processo. Trata-se de um ensaio acerca das possibilidades e limitações do uso desse instrumento no campo da gestão do esporte. $\mathrm{O}$ trabalho encontra-se divido nas seguintes etapas: no primeiro momento, evidenciase os aspectos conceituais que permeiam a gestão do conhecimento. Na sequência, apresentase a aplicabilidade dessa ferramenta de gestão no âmbito da política pública de esporte e lazer, com base nas fases que constituem o ciclo da política.

\section{REFERENCIAL TEÓRICO}

O conhecimento pode promover significativas alterações nos mais variados segmentos da sociedade, como as atividades sociais e econômicas, promovendo adequações no âmbito organizacional ou individual e novas relações entre os sujeitos, dentro e fora do trabalho. De

Perspectivas em Gestão \& Conhecimento, João Pessoa, v. 11, número especial, p. 83-96, mar. 2021. 
acordo com Stankosky (2005), a gestão do conhecimento foi originada pela junção de diversos profissionais especialistas em suas áreas de atuação (gestão, economia, engenharia do conhecimento, ciência cognitiva e engenharia de software).

Nesse interim, Jarrahi e Kangavari (2012) destacam que a ideia principal da gestão do conhecimento é que as organizações possam, efetivamente, maximizar a capacidade de utilização dos saberes existentes dentro e fora da organização, realizando suas atividades. Essa área em questão pode ser definida:

[...] como a criação de um contexto organizacional favorável ao uso e compartilhamento das informações, de modo a reunir e integrar pessoas e/ou organizações que compartilham dados e saberes, construindo conhecimento por meio de suas interações ou desenvolvimento individual e grupal (TOLEDO; FERREIRA; BRAZIL, 2014, p. 38).

Segundo Marteleto (2001), este contexto diversificado proporciona a criação de redes do conhecimento e a melhoria da qualidade na estrutura comunicacional dos ambientes organizacionais. Verifica-se, assim, um impacto pela capacidade inovativa, entendida por Bittencourt (2012) como a virtualização dos saberes, promovida pela "cibercultura", que permite ao homem a criação e participação de uma inteligência coletiva com velocidade nas trocas informacionais. Nessa linha, Nepomuceno e Cavalcanti (2007) afirmam que a internet potencializa a inovação, mas não a concretiza, indicando a necessidade de agregar valores aos conteúdos circulantes no ambiente em questão.

Este novo momento promovido pela internet se caracteriza pela velocidade e eficiência no processo comunicacional com maior volume de trocas das informações em tempo real, gerando novas relações e redes formadas em longas distâncias. Nepomuceno e Cavalcanti (2007) caracterizam esse fenômeno como comunicação de muitos para muitos, facilitado em decorrência da redução na dimensão do tempo e do espaço (BARRETO, 1998), contribuindo na geração de novos saberes, proporcionada pela alta conectividade entre os usuários.

De acordo com Gaspar Filho et al. (2018) a inovação é compatibilizada quando promovida pelo conhecimento através do desenvolvimento qualitativo do esporte no campo social, cultural, político e econômico. Nessa linha de raciocínio, verifica-se que o papel do conhecimento hoje na economia, obriga os agentes econômicos a repensarem as suas estruturas e se organizarem de uma nova forma, se tornando o centro das estratégias de desenvolvimento tecnológico. Neste sentido, direcionar o olhar sobre o papel do conhecimento na gestão do esporte torna-se frutífero para as estratégias de intervenção governamental deste setor.

Esse fato encontra em Schwartz et al. (2014) apoio em relação ao fluxo de novos processos bem como a efetivação da gestão do conhecimento, fomentando e subsidiando planejamentos e implementações de novas ações em políticas públicas, cuja necessidade é aperfeiçoar a relação entre pesquisadores e poder público. Takeuchi e Nonaka (2008, p. 126) afirmam que "os administradores precisam apoiar a criação do conhecimento em vez de controlá-la. Isso se chama promoção do conhecimento". Os autores em questão consideram o conhecimento, partindo dos estudos de Polanyi (1966), como:

- Tácito: pessoal; informal; experimental; intuição; palpite; inspirações; 'percepção' do cliente; insights subjetivos; 'know how'; habilidades técnicas; não é facilmente visível e explicável; difícil de formalizar e comunicar; mais ligado à experiência corporal.

- Explícito: linguagem formal e sistemática; documentado; objetivo; fórmulas científicas; recursos visuais; fitas de áudio; especificações de produtos ou manuais; pode ser

Perspectivas em Gestão \& Conhecimento, João Pessoa, v. 11, número especial, p. 83-96, mar. 2021. 
expresso e compartilhado; rapidamente transmitido; base de dados processado, transmitido, estocado e mantido pela Tecnologia da Informação.

Verifica-se, assim, a ocorrência de um fluxo gerador de ações inovadoras, entendido como o processo de conversão necessário para geração de novos saberes, denominado por Nonaka e Takeuchi (1997) como modelo SECl e sua espiral do conhecimento, conforme a Figura 1 a seguir:

Figura I - Processos de Conversão do Conhecimento.

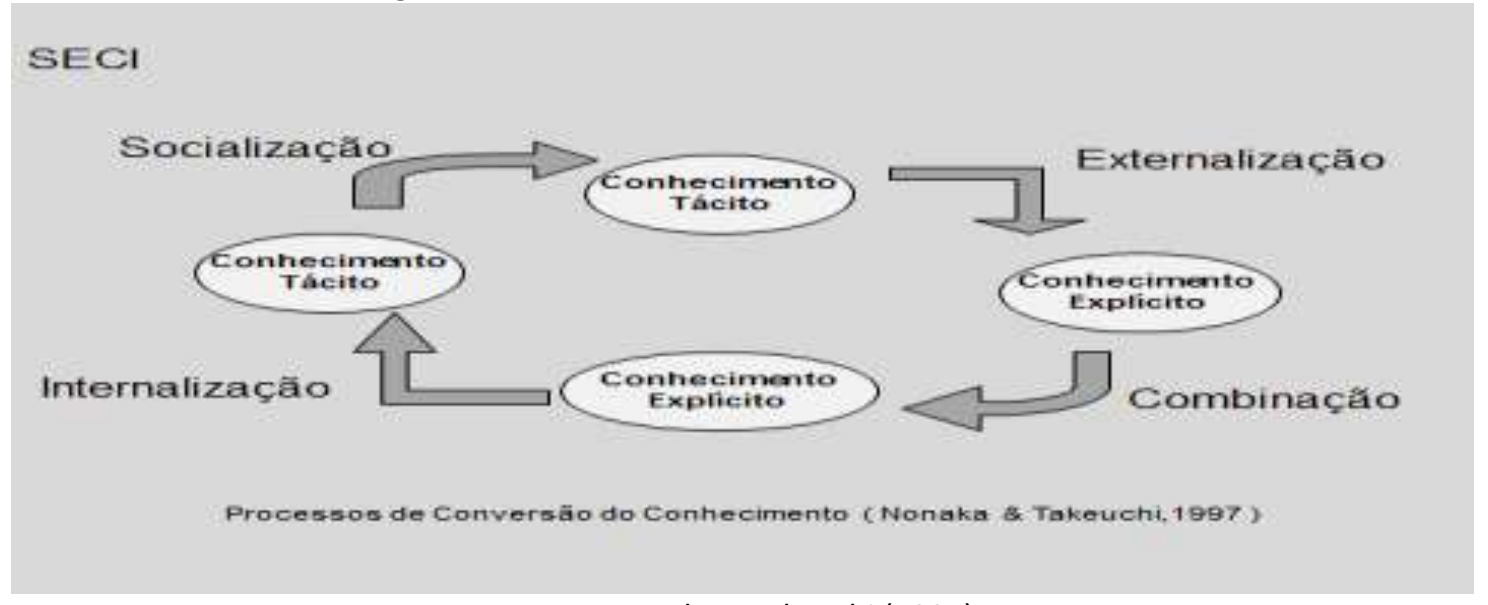

Fonte: Nonaka e Takeuchi (1997)

Em termos pormenorizados, a seguir expõe-se esses processos de conversão do conhecimento. Primeiramente, a "Socialização" representa a conversão do conhecimento tácito em tácito, isso significa que "A criação do conhecimento inicia no processo de socialização, no qual o novo conhecimento tácito é convertido através das experiências compartilhadas na interação social do dia-a-dia" (NONAKA; TAKEUCHI, 1997, p. 96). Já a "Externalização" trata-se da conversão do conhecimento tácito em explícito, ou seja, "o conhecimento tácito é tornado explícito para que possa ser compartilhado com outros e se torne a base de um novo conhecimento, como os conceitos, imagens e documentos escritos" (NONAKA; TAKEUCHI, 1997, p. 97).

A “Combinação" retrata a conversão do conhecimento explícito em explícito:

O conhecimento explícito é coletado do interior ou exterior da organização e, então, combinado, editado ou processado para formar um conjunto mais complexo e sistemático do conhecimento explícito através do processo de combinação. O novo conhecimento explícito é, então, disseminado entre os membros da organização (NONAKA; TAKEUCHI, 1997, p. 97).

Por fim, a "Internalização" é caracterizada pela conversão do conhecimento explícito em tácito:

O conhecimento explícito é criado e partilhado através da organização e então convertido em conhecimento tácito durante o processo de internalização. Este estágio pode ser entendido como práxis, onde o conhecimento é aplicado e usado em situações práticas e torna-se base para novas rotinas (NONAKA; TAKEUCHI, 1997, p. 98).

Posto isto, entende-se que utilizar a gestão do conhecimento como um modelo metodológico de aplicação prática pode promover o alinhamento de decisões e ações dos

Perspectivas em Gestão \& Conhecimento, João Pessoa, v. 11, número especial, p. 83-96, mar. 2021. 
governantes, seja em nível municipal, estadual ou federal (NERY et al., 2018). Os autores em questão apontam adequações que ocorrem em nível organizacional ou individual, estabelecendo novas relações entre os sujeitos, dentro e fora do trabalho na organização, promovidas pela Internet, potencializando a troca de informações e gerando novos saberes. A proposta de um ensaio sobre a temática dedicada à gestão pública do esporte e lazer, se justifica, pois existem poucos estudos sobre a gestão do conhecimento neste campo no Brasil, no qual abordam temáticas acerca da criação do conhecimento no relacionamento intra e interorganizacional (ARANTES, 2018), gestão do fluxo de conhecimentos nas organizações esportivas (NERY, 2017), gestão do conhecimento e os fatores de inovação organizacional (NERY et al., 2018) e a gestão do conhecimento na Rede CEDES (TAVARES; SCHWARTZ, 2013).

Em conformidade com Silva (2002), a gestão do conhecimento necessita ser vista contemplando a complexidade organizacional, balanceada com a participação de profissionais em diferentes características, entendida como "confrontação construtiva", significando um ambiente que não coloque barreiras às especializações, estilos cognitivos e diferentes metodologias. Para Nery et al. (2019), este tema, relevante em diferentes áreas do conhecimento e na prática do campo esportivo, tem sido pouco tratado em termos de pesquisas no universo da gestão do esporte e que sua aplicação seria relevante na construção e implementação de políticas públicas para o esporte brasileiro. Segundo os referidos autores, implicações teóricas e práticas levam à prospecção sobre a inclusão da gestão do conhecimento como ferramenta norteadora em novas formas de discussões para 0 desenvolvimento no campo das políticas públicas.

\section{A GESTÃO DO CONHECIMENTO COMO FERRAMENTA PARA AS POLÍTICAS PÚBLICAS DE ESPORTE E LAZER}

Ao remeter o modelo do ciclo político para compreender os processos inerentes à vida das políticas públicas, cabe ressaltar que, na prática, o mesmo não se configura como uma sequência linear das etapas, ou seja, como um encadeamento estanque e sucessivo, mas enquanto modelo torna-se adequado para se explicar os processos e seu caráter enquanto instrumento de análise (FREY, 2000; CARVALHO, 2003). Em termos complementares, torna-se importante entender que a gestão das políticas públicas ocorre mediante a um processo de fluxo contínuo e de constante interação, possibilitando ajustar e adequar às ações e também modificar significativamente uma determinada política pública (CARVALHO, 2003).

Dados os inúmeros campos de ação de intervenção estatal no cenário brasileiro, alguns campos ainda carecem de estudos e sistematizações que visam contribuir com a institucionalização da gestão do conhecimento enquanto instrumento de gerenciamento das políticas. Nesse contexto, encontra-se o setor esportivo que, aos longos dos anos, obteve espaço significativo nas agendas governamentais, com órgãos específicos para a formulação e implementação de políticas em suas pastas (TOLEDO, 2014), a exemplo da Secretaria Especial de Esporte no âmbito nacional, os órgãos estaduais e as secretarias/departamentos em nível municipal. Estas últimas possuem papel significativo para o desenvolvimento da política de esporte no Brasil, em razão de serem umas das principais estruturas provedoras de ações para o setor, formada por uma infinidade de agentes e redes que apresentam relações diretas nas tomadas de decisões das políticas em nível local (STAREPRAVO; MEZZADRI, 2013).

Nessa linha de raciocínio, pensar na produção e análise de informações, com base em indicadores no âmbito das políticas públicas de esporte torna-se um fator preponderante para qualificar os processos condicionais e contingentes no gerenciamento dessas ações (MENEGALDO, 2019). Destaca-se, dentre esses fatores, que na conjuntura do campo da atividade pública na área esportiva, este setor detém recursos financeiros, recursos humanos, conjunto de normas regulatórias, as políticas propriamente ditas e os resultados e efeitos das

Perspectivas em Gestão \& Conhecimento, João Pessoa, v. 11, número especial, p. 83-96, mar. 2021. 
ações promovidas (TOLEDO, 2014; MENEGALDO, 2019). Esse conjunto de elementos demandam, em certa medida, práticas de gestão do conhecimento que visem contribuir e aperfeiçoar o processo de formulação, implementação e avaliação dessas políticas.

Ainda que pouco explorada no contexto da administração pública, a gestão das informações e do conhecimento na esfera esportiva iniciou, mesmo que parcamente, a ser discutida e compreendida como estratégia para o gerenciamento e desenvolvimento do esporte, principalmente em nível nacional, a partir da criação de centros, redes e sistemas (BOTELHO; MONTEIRO; VALLS, 2007). Embora possa ser questionada a eficiência e a efetividade de tais ações, verifica-se que tais iniciativas demonstram certa movimentação no setor público em torno d gestão do conhecimento, tanto como ferramenta a ser utilizada pelos órgãos governamentais no desenvolvimento das políticas de esporte, quanto para atender mudanças e necessidades organizacionais de transparência, intersetorialidade e inovação tecnológica da gestão pública.

Se por um lado verificamos iniciativas no âmbito nacional, por outro pode se constatar um abismo em relação às práticas de produção de informações no contexto local, tendo em vista o grande quantitativo de municípios brasileiros, muitos desses com baixa capacidade e com fragilidades na gestão pública de esporte (MENEGALDO, 2015; 2019). Em estudo realizado com gestores públicos em municípios de pequeno porte no estado do Paraná, Menegaldo (2015) detectou fragilidades na gestão pública de esporte, tanto pela carência de conhecimentos específicos de gestão para auxiliar no desenvolvimento das atividades por parte dos agentes públicos, como da falta recursos humanos nas secretarias/departamentos, em que gestores acabavam assumindo as funções de gerência e também de execução de políticas públicas de esporte, que somando a outros fatores afetavam a capacidade de gestão desses órgãos públicos. É nessa fenda, que pensar a gestão do conhecimento, logicamente dentro das possibilidades de cada contexto, que práticas ou mesmo inciativas, ainda que rudimentares, podem se tornar ferramentas com potencial para se aprimorar e melhorar 0 gerenciamento das ações esportivas.

Ressalta-se que tal procedimento na gestão é importante para gerar informações não apenas para os envolvidos diretamente com a gestão do esporte (gestores), mas também para outros grupos de interesse, como: especialistas e pesquisadores; treinadores, atletas e árbitros esportivos; órgãos de comunicação social e demais público em geral. Para cada grupo de usuários de informações esportivas há tipos de informações que lhe interessa, assim como para distintas finalidades (CLARKE et al., 2000; BOTELHO; MONTEIRO; VALLS, 2007).

Nesse sentido, as diversas informações que possam existir nesse contexto, tem relação direta e indireta com as fases da política, como um fator que possibilita compreender diversas questões que permeiam a vida de determinada política ou a gestão do esporte no setor público. $O$ Quadro 1 a seguir apresenta os tipos de informações e possíveis fontes para se pensar e refletir sobre práticas e sistemas de gerenciamento do conhecimento no âmbito das políticas públicas de esporte e lazer.

Quadro 1 - Gestão do conhecimento aplicada às fases das políticas públicas de esporte e lazer

\begin{tabular}{|c|c|c|}
\hline Fase & Tipos de Informações & Fonte \\
\hline \multirow{4}{*}{ Formação da agenda } & Percepção dos problemas & Planos de governo \\
\cline { 2 - 3 } & Definição das alternativas & $\begin{array}{c}\text { Planos plurianuais; Leis } \\
\text { Orçamentárias Anuais }\end{array}$ \\
\cline { 2 - 3 } & $\begin{array}{c}\text { Indicadores } \\
\text { socioeconômicos e } \\
\text { demográficos }\end{array}$ & $\begin{array}{c}\text { Informações estatísticas: } \\
\text { IBGE; DATASUS; IPEA }\end{array}$ \\
\cline { 2 - 3 } & Produção legislativa & $\begin{array}{c}\text { Procuradorias; Diários Oficiais; } \\
\text { Arquivos Públicos }\end{array}$ \\
\hline
\end{tabular}

Perspectivas em Gestão \& Conhecimento, João Pessoa, v. 11, número especial, p. 83-96, mar. 2021. 


\begin{tabular}{|c|c|c|}
\hline & Viabilidade técnico-financeira & Corpo técnico-administrativo \\
\hline & Conhecimento técnico-científico & Banco de dados bibliográficos \\
\hline & Aprendizado político & $\begin{array}{l}\text { Relatórios de atividades de } \\
\text { entes governamentais e não- } \\
\text { governamentais }\end{array}$ \\
\hline \multirow{3}{*}{ Formulação de políticas } & $\begin{array}{c}\text { Fluxos de informação } \\
\text { relacionados ao marketing } \\
\text { esportivo }\end{array}$ & $\begin{array}{c}\text { Canais de comunicação: site } \\
\text { oficial; redes sociais; sites } \\
\text { especializados }\end{array}$ \\
\hline & Dados do Aparato Institucional & $\begin{array}{c}\text { Diário oficial; arquivos } \\
\text { públicos } \\
\end{array}$ \\
\hline & $\begin{array}{c}\text { Instrumentos de gestão } \\
\text { financeira esportiva }\end{array}$ & $\begin{array}{l}\text { Planos Plurianuais; Leis } \\
\text { Orçamentárias Anuais }\end{array}$ \\
\hline \multirow{3}{*}{ Implementação } & $\begin{array}{l}\text { Monitoramento da alocação e } \\
\text { execução orçamentária }\end{array}$ & $\begin{array}{l}\text { Leis orçamentárias Anuais; } \\
\text { Relatórios Resumidos de } \\
\text { Execução Orçamentária }\end{array}$ \\
\hline & $\begin{array}{c}\text { Gestão dos espaços e } \\
\text { equipamentos esportivos }\end{array}$ & $\begin{array}{c}\text { Diagnósticos da infraestrutura } \\
\text { esportiva }\end{array}$ \\
\hline & Gestão dos recursos humanos & $\begin{array}{l}\text { Relatórios administrativos do } \\
\text { corpo técnico da gestão }\end{array}$ \\
\hline \multirow{3}{*}{ Avaliação } & $\begin{array}{c}\text { Demandas dos representantes } \\
\text { esportivos }\end{array}$ & Fóruns; Conferências \\
\hline & $\begin{array}{c}\text { Pareceres da comunidade sobre } \\
\text { pautas específicas do esporte e } \\
\text { lazer }\end{array}$ & Audiências; Reuniões \\
\hline & $\begin{array}{l}\text { Avaliação dos beneficiados e } \\
\text { corpo técnico }\end{array}$ & Questionários \\
\hline
\end{tabular}

Fonte: Elaborado pelos autores (2020)

O quadro apresenta diversos dados que podem subsidiar os gestores esportivos conforme os objetivos delineados. Sendo assim, a análise de tais dados depende diretamente da estratégia da organização acerca da finalidade para com as informações obtidas.

Em relação ao processo de formação da agenda, acredita-se na possibilidade do levantamento de informações correlatas à percepção dos problemas do esporte e lazer, na perspectiva pública com base nas propostas elencadas nos planos de governo dos candidatos eleitos durante os processos eleitorais. Sendo assim, pode-se estabelecer uma janela de oportunidade para a compreensão das prioridades delineadas pelas diversas representações político-partidárias que configuram o atual panorama político-partidário. Desta forma, tornase possível corroborar com Stewart (1998), que o conhecimento é mais valioso que outros recursos que permeiam as tomadas de decisões.

Consequentemente, o fluxo de informação relacionado à definição das alternativas corresponde à identificação das informações inseridas nas peças orçamentárias produzidas pela administração pública. Além disso, os indicadores socioeconômicos servem de ferramentas de direcionamento e para a magnitude das ações por meio do diagnóstico das prioridades relacionadas ao quantitativo e à distribuição geográfica das ações a serem desenvolvidas. Ao mesmo tempo, torna-se necessário a utilização de dados secundários obtidos por meios dos relatórios das atividades de gestão, os quais poderão colaborar com a redução de certo grau de subjetividade da análise em questão, para a formulação de alternativas para as ações.

Ao levar em consideração os dados inseridos na produção legislativa relacionada ao esporte e lazer no processo de formação da agenda, será possível o entendimento sobre as possibilidades e limitações jurídicas das ações a serem implantadas e, posteriormente, a identificação das lacunas existentes no campo jurídico acerca da sustentação legal da política

Perspectivas em Gestão \& Conhecimento, João Pessoa, v. 11, número especial, p. 83-96, mar. 2021. 
esportiva. O conhecimento técnico-científico poderá subsidiar a tomada de decisão sobre a viabilidade técnico-financeira do planejamento esportivo. Para tal, torna-se salutar o levantamento e a sistematização dos conhecimentos que permeiam a dinâmica em questão. Outro ponto a ser destacado refere-se à organização de informações com base no aprendizado político de experiências exitosas no âmbito da gestão esportiva nacional e internacional.

Ainda que se reconheça o esporte enquanto área de atuação e promoção de políticas públicas, com grande acervo de estudos que procuram discutir sobre a temática, verifica-se uma carência de pesquisas que busquem analisar o papel da gestão do conhecimento frente à dinâmica política ora apresentada.

De acordo com Colauto e Beuren (2003), os três processos de aprendizagem nas organizações são: aquisição e desenvolvimento de conhecimentos, disseminação e construção de memórias em um único processo coletivo de elaboração de competências necessárias à organização. Desta forma, pensar a gestão do esporte na perspectiva da gestão do conhecimento perpassa pela compreensão da dinâmica de apropriação das informações que permeiam a tomada de decisão correlata a política de esporte, tais como: indicadores socioeconômicos; viabilidade técnico-financeira das ações propostas e, diagnóstico dos elementos que compõem a política. Além disso, torna-se necessário ampliar o acesso ao conhecimento acerca do fluxo de conhecimento produzido ao longo da gestão por meio da emissão de relatórios das atividades, campanhas de divulgação, realização de fóruns e conferências, entre outros.

Todavia, deve-se considerar que o processo de apropriação da gestão do conhecimento encontra-se alicerçado na relação estabelecida entre o posicionamento dos agentes inseridos na gestão do esporte com as condições estruturais existentes, partindo-se da premissa que existe uma limitação desses agentes acerca das infinitas variáveis que influenciam as diversas etapas do ciclo político. Neste sentido, acredita-se na intensificação dessa relação com base na ampliação do contato com novas experiências na área, formação profissional permanente e agrupamento do maior número de informações que possam auxiliar o processo das tomadas de decisões por parte dos gestores esportivos.

Para Teixeira Filho (2000), o conhecimento passa a ser avaliado através das deliberações que são fomentadas, ou seja, quanto maior o conhecimento sobre determinada área, maior a possibilidade de decisões mais significativas. Neste sentido, o autor em questão revela que o conhecimento se encontra associado à ação, isto é, o discernimento provoca o desencadeamento de atividades correlatas às demandas do campo da gestão. Logo, o espectro sinérgico se apresenta como o processo de potencialização das perícias táticas e experiências individuais dos diversos agentes que atuam em um determinado setor, com vistas à redução dos danos inerentes à gestão ineficiente, bem como a melhoria do grau de satisfação dos beneficiários e do corpo técnico envolvido no referido processo. Neste sentido, as organizações atuam como ferramentas singulares para o desenvolvimento desse espectro, ao levar em consideração a necessidade de articulação entre as informações e tecnologias disponíveis perante a dinâmica em questão.

Em relação à avaliação da gestão do conhecimento, Colauto e Beuren (2003) elencam os seguintes indicadores: crescimento/inovação, eficiência e estabilidade, podendo-se considerar estes como parâmetros do processo de gestão do conhecimento, ou seja, auxiliam a tomada de decisão estratégica dos gestores no sentido de otimizar as ações a serem desenvolvidas e delineadas no curso da gestão. Além disso, possibilitam a identificação e medição de aspectos relacionados à referida gestão, operacionalizando a observação e constituindo um retrato sobre a realidade observada.

A gestão do conhecimento aplicada ao processo de formulação da política encontra-se vinculada à necessidade do estabelecimento de uma série de ações que possam otimizar e auxiliar os formuladores de política. Para Teixeira Filho (2000), o conhecimento encontra-se

Perspectivas em Gestão \& Conhecimento, João Pessoa, v. 11, número especial, p. 83-96, mar. 2021. 
vinculado à ação e, consequentemente, pode conduzir o processo das tomadas de decisões relacionado aos elementos que compõem a gestão. Neste cenário, um caminho possível seria o mapeamento das atividades de divulgação e campanhas publicitárias com vistas à reorganização do fluxo de conhecimento a ser disponibilizado junto ao público beneficiado pela política esportiva. Além disso, deve-se reconhecer as limitações do aparato institucional, responsável pelo fomento da política em questão, no sentido de potencializar os mecanismos disponíveis, bem como superar os obstáculos existentes. Vale ressaltar que o aparato institucional, por si só, não gera resultados significativos acerca da gestão do conhecimento, tendo em vista que tal elemento possibilita a estrutura necessária à geração de conteúdos.

A organização do fluxo de informação dos instrumentos de política relacionados à gestão financeira esportiva também se apresenta como uma estratégia para a materialização da gestão do conhecimento. Neste contexto, pode-se evidenciar as peças orçamentárias como uma fonte elementar para o diagnóstico de dados sobre as condições econômicas que envolvem a gestão do esporte. No que se refere a implementação, considera-se a necessidade de monitoramento das informações que circulam a gestão dos espaços e equipamentos esportivos, gestão dos recursos humanos e gestão financeira do setor abordado. Para tal, a captura das experiências do corpo técnico inserido no contexto é um fator preponderante, quanto a sua utilização como parâmetro para o desenvolvimento de novas estratégias.

Em relação à fase de avaliação das políticas, a produção de informações e gestão do conhecimento nas políticas de esportes possibilitam oferecer parâmetros partindo-se de indicadores que propiciem perceber a avaliação à partir de uma visão sistêmica, ou seja, compreender as fases e os elementos presentes em cada parte da política, sem deixar de analisá-la, levando-se em consideração sua complexidade e totalidade. Sendo assim, tal aplicação no âmbito da gestão do conhecimento permite contemplar não apenas todas as fases da política, mas também considerar os grupos envolvidos nesse processo, que vão desde diagnosticar demandas sociais e níveis de satisfação dos beneficiários da política, implementar mecanismos de monitoramento para verificar o desenvolvimento dos projetos, avaliar os elementos contingentes e condicionais que permeiam a gestão pública, dentre outros fatores que interferem direta e indiretamente no desenvolvimento das políticas de esporte e lazer (MENEGALDO, 2019).

A partir desses elementos, entende-se que a gestão de conhecimento é um processo importante para possibilitar a avaliação das políticas públicas de esporte, em que as informações levantadas sobre as diversas variáveis permitem realizar cruzamentos dos dados que, em certa medida, possibilitam desenvolver o aprendizado organizacional dos processos e propicia a tomada de decisão de modo instrumental ou político, por parte dos gestores e demais agentes políticos presentes nesse meio (FARIA, 2005, MENEGALDO, 2019).

Vale destacar que todo e qualquer sistema de avaliação só terá eficácia por meio de análises comparativas entre indicadores de gestão esportiva correlata a administrações passadas ou indicadores de entidades governamentais similares, colocando em evidência o fator "político" no desenvolvimento das políticas públicas e demais relações de ordem do contexto local e global.

\section{CONSIDERAÇÕES FINAIS}

A gestão do conhecimento se apresenta como uma ferramenta capaz de potencializar a sinergia necessária à gestão do esporte, por meio de um modelo gerencial de compartilhamento sistematizado de criação e disseminação de informações que possa colaborar com a ampliação da efetividade das ações desenvolvidas nas diversas fases do ciclo das políticas públicas de esporte e lazer.

Perspectivas em Gestão \& Conhecimento, João Pessoa, v. 11, número especial, p. 83-96, mar. 2021. 
Nesta perspectiva, constata-se a necessidade de articulação da produção científica que permeia a temática com as ações desenvolvidas pelos gestores esportivos. Desta forma, tornase possível visualizar um terreno fértil para o estabelecimento de ações voltadas à formação continuada na gestão do esporte com vistas à possibilidade de ressignificação do processo de planejamento, execução e avaliação das políticas públicas do esporte em contextos distintos. Diante do panorama e das reflexões apresentadas, vislumbra-se a possibilidade de inovação na gestão pública correlata ao esporte e lazer, ao levar em consideração a busca pelo entendimento acerca da dinâmica e os padrões de mudança da gestão do esporte ao longo do tempo, com base na gestão do conhecimento. Outro fator importante relaciona-se à possibilidade de refletir sobre as ações desenvolvidas pelos gestores, proporcionando assim, novos horizontes para a política esportiva, no intuito de potencializar as atividades inerentes à área.

Desta forma, acredita-se que a ausência de conhecimentos inerentes à gestão pública, em especial, ao processo de planejamento, execução e avaliação das políticas públicas de esporte e lazer, se apresenta enquanto fator limitante do desenvolvimento de ações significativas para o setor. Portanto, pensar na gestão do conhecimento no setor público do esporte são passos que devem ser dados para melhorar o desenvolvimento das políticas do setor, em termos de se obter um conhecimento sistêmico sobre esse campo de intervenção. Este fato possibilita a realização de políticas eficientes e eficazes, que assegurem minimamente uma coerência das demandas sociais e as possibilidades administrativas, para que possam orientar os agentes públicos e, ao mesmo tempo fornecer aprendizado desses processos aos profissionais, podendo vir a resultar no favorecimento da institucionalização da gestão do conhecimento no âmbito da gestão pública de esporte.

\section{REFERÊNCIAS}

ARANTES, Alexandre Ribeiro. Criação do Conhecimento intra e interorganizacional em organizações esportivas. 2018. 130 f. Dissertação (Mestrado em Ciências) - Escola de Educação Física e Esporte, Universidade de São Paulo, São Paulo, 2018.

BARRETO, Aldo de Albuquerque. Mudança estrutural no fluxo do conhecimento: a comunicação eletrônica. Ciência da Informação, Brasília, v. 27, n. 2, p. 122-127, 1998.

BATISTA, Fábio Ferreira. Governo que aprende: gestão do conhecimento em organizações do executivo federal - Texto para discussão no 1022. Brasília: IPEA, 2004. Disponível em: https://www.ipea.gov.br/portal/images/stories/PDFs/TDs/td 1022.pdf. Acesso em: 01 jun. 2020.

BITTENCOURT, Renato Nunes. Virtualização dos saberes. Portal Ciência e Vida: Filosofia. Ano VI, n. 68, p. 17-23, 2012.

BOTELHO, Maria Antônia; MONTEIRO, Ana Maria; VALLS, Valéria. A gestão do conhecimento esportivo: a experiência da biblioteca da Seme. Ciência da Informação, Brasília, v. 36, n. 1, p. 175-188, 2007.

CAPELLA, Ana Cláudia Niedhardt. A formulação de políticas públicas. Brasília: Enap, 2018. 
CARVALHO, Sonia Nahas de. Avaliação de programas sociais: balanço das perspectivas e contribuição para o debate. São Paulo em Perspectiva, São Paulo, v. 17, n. 3-4, p. 185-197, jul./dez. 2003.

CLARKE, Nerida et al. Manual do centro de informação desportiva. Tradução do Centro de Estudos e Formação Desportiva. Lisboa: Instituto Nacional de Formação e Estudos do Desporto, 2000.

COLAUTO, Romualdo Douglas; BEUREN, Ilse Maria. Proposta para avaliação da gestão do conhecimento em entidade filantrópica: o caso de uma organização hospitalar. Revista de Administração Contemporânea, Curitiba, v. 7, n. 4, p. 163-185, dez. 2003.

COSTA, Frederico Lustosa; CASTANHAR, José César. Avaliação de programas públicos: desafios conceituais e metodológicos. Revista de Administração Pública, Rio de Janeiro, v. 37, n. 5, p. 969-992, set./out. 2003.

FARIA, Carlos Aurélio Pimenta de. A política da avaliação de políticas públicas. Revista Brasileira de Ciências Sociais, São Paulo, v. 20, n. 59, p. 97-109, out. 2005.

FREY, Klaus. Políticas públicas: um debate conceitual e reflexões referentes à prática da análise de políticas públicas no Brasil. Revista Planejamento e Políticas Públicas, Brasília, n. 21, p. 211-259, jun. 2000.

GASPAR FILHO, V. J. et al. Buscando um novo caminho para a Gestão do Esporte: Mapeamento e Identificação dos Grupos de Estudos e Pesquisas em Gestão do Conhecimento no Brasil. In: V Semana Do Conhecimento E Jornada De Iniciação Científica: Pesquisa, Tecnologias e Cidadania, v.5, p. 62, 2018, São Lourenço. Anais [...] São Lourenço: V Semana do Conhecimento e Jornada de Iniciação Científica 2018.

IBGE. Pesquisa de Informações Básicas Municipais. Perfil dos Municípios Brasileiros, Esporte 2016. Rio de Janeiro: IBGE, 2016.

JARRAHI, Ali; KANGAVARI, Mohammad Reza. An Architecture for Context-Aware Knowledge Flow Management Systems. International Journal of Computer Science Issues, v. 9, n. 3, p. 4051, 2012.

MARTELETO, Regina Maria. Análise de redes sociais: aplicação nos estudos de transferência da informação. Ciência da Informação, Brasília, v. 30, n. 1, p. 71-81, jan./abr. 2001.

MENEGALDO, Pedro Henrique Iglesiaz. Políticas públicas de esporte e lazer na microrregião de Ivaiporã, PR: concepções e ações dos gestores públicos municipais. 2015. 149 f. Monografia (Graduação em Educação Física) - Universidade Estadual de Maringá, Campus Regional do Vae do Ivaí, Ivaiporã, 2015.

MENEGALDO, Pedro Henrique Iglesiaz. Avaliação de políticas públicas de esporte: uma interlocução com os agentes públicos municipais. 2019. 124 f. Dissertação (Mestrado em Educação Física) - Universidade Estadual de Maringá, Maringá, 2019.

NEPOMUCENO, Carlos; CAVALCANTI, Marcos. O Conhecimento em Rede: como implantar projetos de inteligência coletiva. Rio de Janeiro: Editora Campus, 2007.

Perspectivas em Gestão \& Conhecimento, João Pessoa, v. 11, número especial, p. 83-96, mar. 2021. 
NERY, Luiz Carlos Pessoa. Gestão do conhecimento como ferramenta para a gestão do esporte: o fluxo do conhecimento como agente potencializador de inovação organizacional. 2017. 135 f. Tese (Doutorado em Ciências do Exercício e Esporte) - Universidade do Estado do Rio de Janeiro, Rio de Janeiro, 2017.

NERY, Luiz Carlos Pessoa et al. Gestão do conhecimento e os fatores de inovação organizacional na gestão do esporte baseado no fluxo de conhecimento: uma revisão sistemática. Brazilian Journal of Information Science: Research Trends, v. 12, n. 3, p. 64-85, 2018.

NERY, Luiz Carlos Pessoa et al. Gestão do Conhecimento e Políticas Públicas no esporte: Produção de grupos de estudos e pesquisas em gestão do esporte no Brasil. In: 10 Congresso Brasileiro de Gestão do Esporte. Anais [...] São Paulo: 10 CBGE, 2019.

NONAKA, Ikujiro; TAKEUCHI, Hirotaka. Criação de conhecimento na empresa: como as empresas japonesas geram a dinâmica da inovação. Rio de Janeiro: Campus, 1997.

OCDE. Survey of Knowledge Management Practices for Ministries/Departments/Agencies of Central Governments in OECD Member Countries. Paris, França: Organization for Economic Co-operation and Development (OCDE), 2002.

POLANYI, Michael. The tacit dimension. Chicago: University of Chicago Press, 1966.

RAMOS, Marília Patta; SCHABBACH, Letícia Maria. O estado da arte da avaliação de políticas públicas: conceituação e exemplos de avaliação no Brasil. Revista de Administração Pública, Rio de Janeiro, v. 46, n. 5, p. 1271-1294, 2012.

ROSENBERG, Gerson; OHAYON, Pierre; BATISTA, Fabio Ferreira. Gestão do conhecimento em organizações públicas de saúde no Brasil: diagnóstico de práticas. Revista do Serviço Público, Brasília, v. 59, n. 1, p. 43-60, 2008.

SCHWARTZ, Gisele et al. Políticas públicas de esporte e lazer e gestão da informação: incidência da Rede CEDES como foco em pesquisas acadêmicas. Motrivivência, v. 26, n. 42, p. 86-97, 2014.

SECCHI, Leonardo. Políticas Públicas: conceitos, esquemas de análise, casos práticos. São Paulo: Cengage Learning, 2010.

SILVA, Sergio Luis. Informação e Competitividade: a contextualização da gestão do conhecimento nos processos organizacionais. Ciência da Informação, Brasília, v. 31, n. 2, p. 142-151, 2002.

STANKOSKY, Michael. Creating the discipline of knowledge management: The latest in university research. New York: Routledge, 2005.

STAREPRAVO, Fernando Augusto; MEZZADRI, Fernando Marinho. Gestão Pública de Esportes no Municípios do Estado do Paraná (Brasil). In: AGUADO, D. M. La gestión desportiva municipal en Iberoamérica: Historia, teoría y práctica. Madrid, Spain: Librerias Deportivas Esteban Sanz, S. L., 2013.

Perspectivas em Gestão \& Conhecimento, João Pessoa, v. 11, número especial, p. 83-96, mar. 2021. 
STEWART, Thomas A. Capital intelectual: a nova vantagem competitiva das empresas. 7. ed. Rio Janeiro: Campus, 1998.

SZEZERBICKI, Arquimedes da Silva. A Gestão do Conhecimento em Equipes de Alta Performance: $O$ caso do Clube Atlético Paranaense. 2006. 135 f. Dissertação (Mestrado em Engenharia de Produção) - Universidade Tecnológica Federal do Paraná, Campus Ponta Grossa, Ponta Grossa, 2006.

TAKEUCHI, Hirotaka.; NONAKA, Ikujiro. Gestão do conhecimento. Porto Alegre: Bookman, 2008.

TAVARES, Giselle Helena; SCHWARTZ, Gisele Maria. Gestão da informação e do conhecimento em políticas públicas: ações realizadas pela rede CEDES/ME. Movimento, Porto Alegre, v. 19, n. 4, p. 207-226, out/dez. 2013.

TEIXEIRA FILHO, Jaime. Gerenciando conhecimento. Rio de Janeiro: Senac, 2000.

TOLEDO, Heglison Custódio; FERREIRA, Guilherme Novaes Pinto; BRAZIL, Gustavo Paraná Paes. Desenvolvimento da Análise de Desempenho Esportivo no Voleibol de Alto Rendimento no Contexto da Gestão do Conhecimento. Podium Sport, Leisure and Tourism Review, v. 3, n. 3, p. 36-44, 2014.

TOLEDO, Renata Maria. As políticas públicas e o direito "social" ao esporte: uma análise a partir do estado do Paraná (1995-2010). 2014. 276 f. Tese (Doutorado em Sociologia) Universidade Federal do Paraná, Curitiba, 2014.

Recebido em/Received: 08/01/2021 | Aprovado em/Approved: 22/02/2021

Perspectivas em Gestão \& Conhecimento, João Pessoa, v. 11, número especial, p. 83-96, mar. 2021. 